\title{
Analysis on Closed-loop Control System of Class F Gas Turbine
}

\author{
Lei Shi ${ }^{\mathrm{a}}$,XiaomengChen ${ }^{\mathrm{b}}$ \\ Beijing Jingneng Gaoantun Thermal Power Co.Ltd, Beijing City,China \\ ahust_shilei@126.com, ${ }^{b}$ chenxiaomeng@powerbeijing.com
}

Keywords: Class F Gas Turbine, Closed-loop Control, ,Run-up,OTC, Siemens' SGT5-4000F

\begin{abstract}
Gas Turbine engine is the most advanced large equipment in the world; the automatic control is a very important matter. The closed-loop is the core of automatic control, and it is also the most complex. Jing Neng Gaoantun gas power plant installed Siemens' SGT5-4000F gas turbine. As a typical model of Class F gas turbine, closed-loop followed many classical designs of Siemens. As a technical stuff in this industry, we have to know the strategy and principle of the Closed-loop Control System, thus we can analyze and diagnosis operation better.
\end{abstract}

\section{Introduction}

A gas turbine, also called a combustion turbine, is a type of internal combustion engine. It has an upstream rotating compressor coupled to a downstream turbine, and a combustion chamber in between [1]. Industrial gas turbines differ from aeronautical designs in that the frames, bearings, and blading are of heavier construction. They are also much more closely integrated with the devices they power- often an electric generator - and the secondary-energy equipment that is used to recover residual energy (largely heat) [2-4]. Gas turbine, friendly for the environment, is widely applied in power generation area. Control system plays a key role during running gas turbine, considering the safety and efficiency[6-8]. This paper introduces on a closed-loop control system for Gas Turbine.

\section{Control models}

The gas turbine closed-loop control partof Seimens SGT5-4000F gas turbine control system are implemented within FM458 controller, the controller has rapid processing capabilities, the main protection of gas turbine and closed-loop control functions, this section is equal to the steam turbine DEH control system. Closed-loop Control System basically has the following several aspects: Run-up function, Speed/load controller, Exhaust temperature controller, Limit load controller, Compressor pressure ratio limit controller, IGV temperature controller, Valve lift controller and etc.

The basic function of gas turbine closed-loop control module. The closed-loop control system has the following four basic functions: (1) Control pilot gas to ensure the stability combustion and NOx emissions; (2) Control of gas turbine rotor accelerate process; (3) Control of the gas turbine speed and load; and (4) Control the turbine inlet temperature of gas turbine[7].

Minimum selection control of Seimens gas turbine closed-loop control system.Siemens gas turbine closed-loop control module followed Siemens' typical design concept - the minimum selection control function. Under various operating conditions, the amount of fuel control are controlled by RAK0F minimum selector, RAK0F is a macro command module in Siemens T3000 control system, wherein the minimum value of several input will be selected as the output value(this macro command module dedicated to amount of fuel in the combustion control setting, which also has the functions like simulation)[7]. 


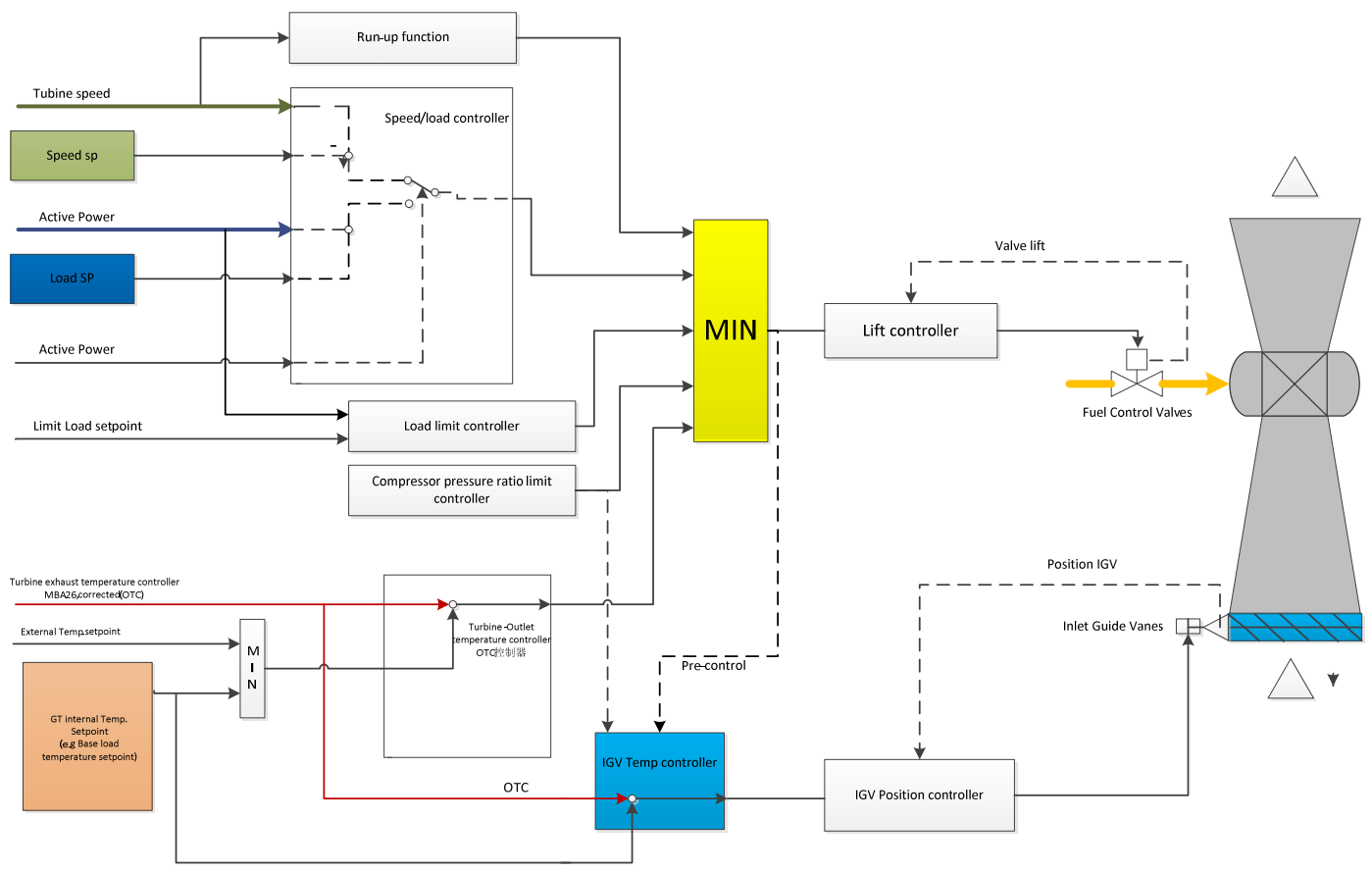

Figure 1. General gas turbine control function

After start up, the Run-up function controller will control the rotor acceleration according to pre-set value, the outlet temperature and rotation speed rise with it. When the rotor speed reach up to 50.25 $\mathrm{Hz}$, start up control is finished, and speed controller starts to work, the generator is working at FSNL(full speed no load) mode, and get ready to connect to grid. When generator is connecting to grid, speed controller will quit operation (under this working condition, this circuit will implement function of primary frequency adjustment), and gas turbine will be transferred to load control mode. Before the gas turbine reach to base load, because the outlet temperature does not reach activated value of turbine-outlet temperature controller, the function of outlet temperature control will quit, gas turbine will be controlled by speed/load controller under this working condition. When the output reach to a certain degree, the outlet temperature reach activated value, IGV opening will reach to $100 \%$,the OTC controller will start to work, and speed/load controller will quit by selection of RAK0F minimum selector function, due to the influent of ambient temperature, the upper limit of load is controlled by OTC controller, the load cannot be raised [7]. These four control mode is the main operating mode of gas turbine, load limit controller and compressor pressure ratio limit controller is only activated under special working situation. In whole operating process, there is only one circuit is controlled MIN controller, then this circuit is gas turbine present operating mode.

A general control system, as shown in Figure 1, contains five control functions, and RAK0F minimum selector will select the minimum value of 5 control functions as RAK0F output, as the executive control commands sent to the fuel control system.

Every time there is only one control function to control gas turbine fuel flow at present. As shown in figure 1 that these controllers will be input of Minimum selector (MIN), its output will be the input fuel control system, the minimum value can provide the safest mode to operation [8].

Typical functional controller of gas turbine closed-loop control system. Gas turbine has its own characteristics in different stages of different operating conditions which needs different function of the controller to control. According to the function is divided into: run-up controller, speed/load controller, exhaust temperature controller (OTC), compressor pressure ratio limit controller, load limit control. Here are a few introduction of Siemens class F typical closed loop control. 


\section{A. Run-up controller}

Gas turbine will run-up by starting frequency controller (SFC) drag until the mass flow of compressed air which produced by compressor and fuel gas flow controlled by run-up controller reach to a sufficient value and the turbine can be rotated by output of combustion chamber. The main function of run-up controller is to raise the rotation speed from turning gear speed to rated speed, during this process, there is a different acceleration rate at corresponding frequency, the value of acceleration rate depends on fuel gas flow and starting mode (normal staring and black starting). Except this run-up function, the minimum fuel gas flow which controlled by MIN will also impact the output of run-up controller, this output can protect gas turbine from hurt by excess fuel gas. The fuel gas flow is adjusted by MIN according to fuel gas setting value, when the unit reach to rated speed, speed controller will start, and start up controller quit. Run-up controller use following mode to control fuel gas flow: the relationship of speed and fuel gas flow, see figure 3, the unit of speed is $\mathrm{Hz}$, the unit of fuel gas flow is a relative amount, the fuel gas value is 0 when ESV closed, the fuel gas flow in the chart will the output of run-up controller when ESV open. The logic of run-up controller as figure 2, there are two curves in run-up controller, the two curves will be selected by MIN as output, then control the flow of premix gas and pilot gas during run-up until the speed reach up to $3000 \mathrm{rpm}$, then the run-up controller quit.

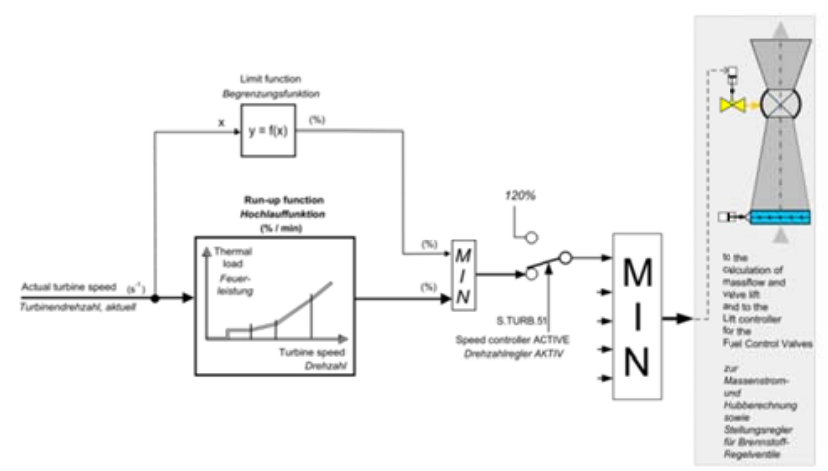

Figure 2. Run-up controller function diagram

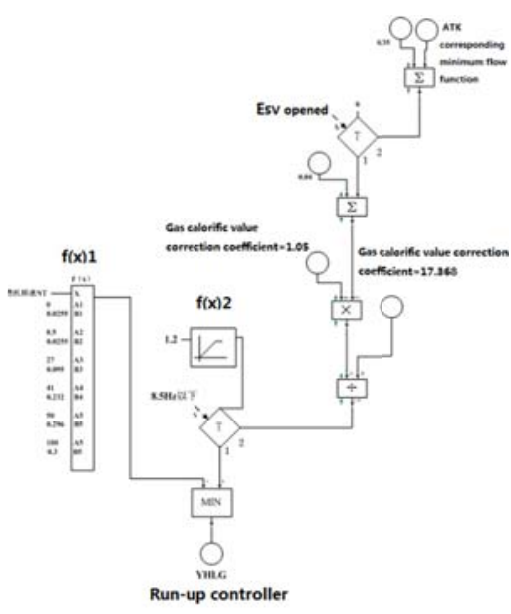

Figure 3. Run-up controller function diagram

Curve 1: function of actual speed and fuel gas flow, the purpose of this curve is ensure the fuel gas flow keep in a reasonable range at different speed range during speed up process, it can avoid excess fuel gas flow. This curve is a safety value curve, this curve will not be used in normal situation.

Curve 2: the curve for speed and fuel gas flow, the control of fuel gas flow during speed up, premixed valve, pilot valve subject to this curve. This curve is divided to four stage according to this curve, in every stage, run-up controller use different accelerate rate.

\section{B. Speed/Load controller}

Speed/Load controller is double variable controller, it control target deviation of speed and load in parallel. Before connect to grid, speed/load controller only control speed, after connect to grid, it will shift to load control. Speed/load controller will control the valve of fuel gas piping by minimum logic, the main target is premixed valve, the pilot gas is only for stable combustion, this control is open loop,it will be impacted by exhausting temperature and IGV opening. This controller's main task is adjust speed and load under bellowing working situation:gas turbine speed adjustment before connect to grid, load adjustment and load rejection control after connect to 
grid.Speed /load controller is equipped with function of primary frequency adjustment.

Speed/load control logic as shown in figure 4, this controller is double variable controller, the gas turbine speed will be adjusted by speed circuit before connect to grid. After connect to grid, load control function will be used to adjust load, and speed control function will be used to primary frequency adjustment. When the primary frequency controller starts to run, speed controller and load controller will run in parallel. In order to meet the requirement of speed adjustment, the speed circuit and load circuit apply former feedback mode[9].
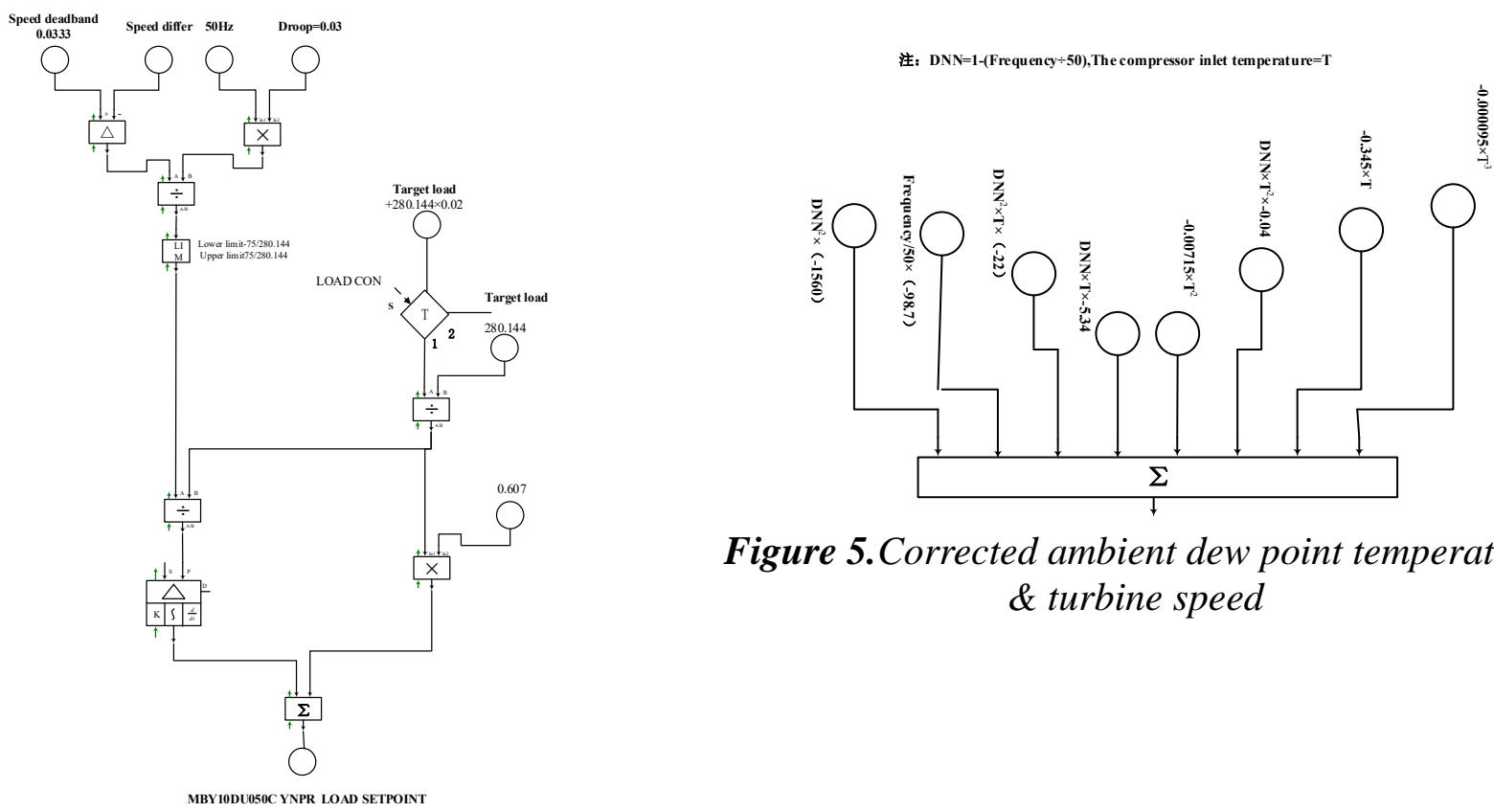

Figure 5.Corrected ambient dew point temperature \& turbine speed

Figure 4. Speed $\mid$ Load controller logic diagram

\section{a) OTC controller-Outlet Temperature Corrected controller}

The temperature of combustion chamber and inlet of turbine is very important for safety work, combustion chamber do not equipped thermos detector due to limitation of high temperature and manufacturing process, actually the control of temperature of combustion is indirect controlled by exhausting temperature. Outlet temperature controller (OTC) adjust the exhausting temperature according to valid temperature setting value.

This controller will control the exhausting temperature in an allowable range by adjust the fuel gas flow. When the unit is running under combine cycle situation, the OTC controller will be activated by coordination control mode, it can match the exhausting temperature and the magin of temperature rise of boiler and steam turbine in a definite load range. OTC controller is also a closed loop controller, and adjust the fuel gas flow through center MIN logic circuit.because the inlet of turbine has no temperature measurement point, it is indirect indicated by exhausting temperature, so the exhausting temperature is very important.in the circuit of OTC, the control target is the corrected temperature (ATK), it will correct exhausting temperature (TOT) by some other parameters such as temperature of compressor inlet the corrected exhausting temperature (TOT)is an average value of 24 twin thermocouples.

After summing correctionof inlet temperature of compressor and turbine speed and ambient dew point temperature \& turbine speed, the PV will be a procedure value of OTC. These two corrected formula Figure 5.

This setting point is consist of three parts, these three parts will be selected as OTC setting point by minimum selection, and control exhausting temperature in real time to secure the gas turbine.

Part I: TSX temperature setting: in the stage of steam turbine starting, run-up, running at primary 
load after connect to grid, in order to ensure the pressure and temperature of boiler in an allowable range, and the inlet pressure, temperature, steam flow of steam turbine in a reasonable range, the coordinated control system will calculate a temperature as the setting point of OTC by precess temperature control circuit (TSX), because the setting point is very low, the inlet temperature controller of gas turbine will be activated advanced, the load controller will be shifted to OTC controller by MIN selector, thus it will limit the load of gas turbine. When the load of steam turbine rise enough to connect to gird, it will use same logic to ensure connect to grid successfully, otherwise the load rise of steam turbine will cause the load of gas turbine decrease in coordinated control mode, and the load of gas turbine decrease will continue cause the load of steam turbine change, sequentially there is a big fluctuate of unit. The bypass of TSX will be closed after steam turbine connect to grid and run stably, this setting point will be expired, OTC control circuit only be impacted by OTC setting point, certainly the setting point for protect boiler TSMAX will be effect all the time.

$$
\begin{gathered}
\text { MBY01DU081C } \\
\text { TSX from CCS }
\end{gathered}
$$

MBA26FT901_XQ03

$\Sigma$

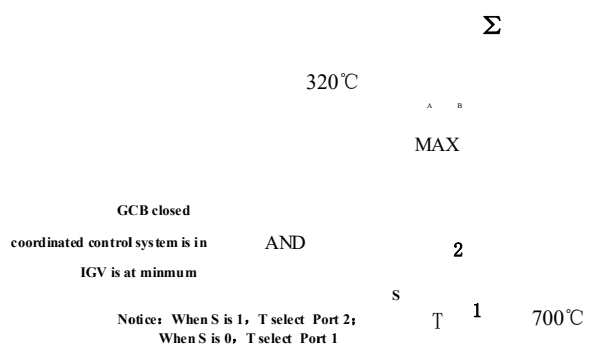

Figure 6.TSX temperature setting

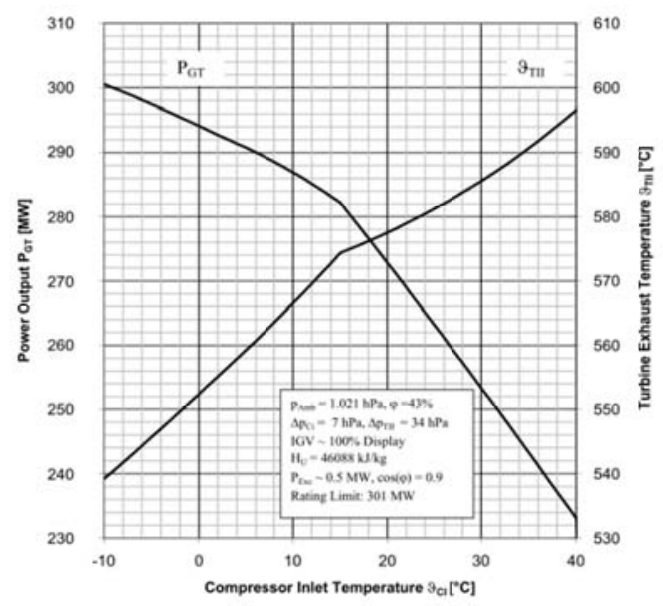

Figure 8.Performace curve of gas turbine output
MBY01DU081C

TSMAX from CCS

MBA26FT901_XQ03

ATK

MAX

Figure 7. TSMAX temperature setting block diagram

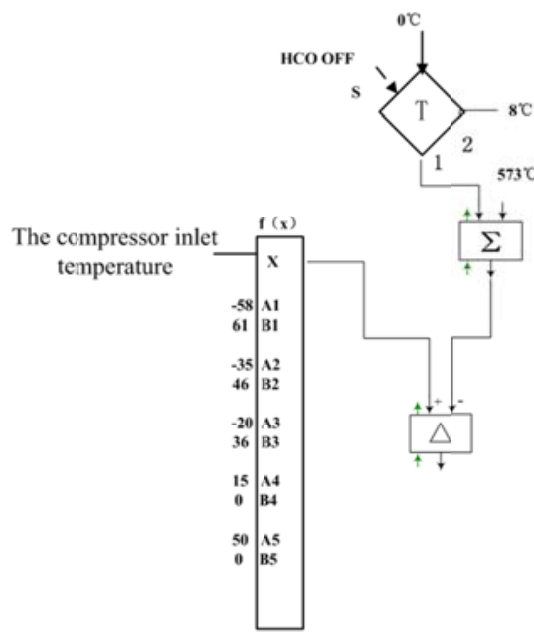

Figure 9.Compressor inlet temperature setting function

Part II: TSMAX temperature setting: under combine cycle situation, in order that the temperature of high pressure steam and middle pressure steam does not exceed the limitation, the coordinated control system will calculate a temperature OTC setting point, thus ensure the OTC does not exceed the maximum of boiler, this setting point is very big, in normal situation this point will not be activated. 
Part III: Corrected OTC setting: according to the correspondence of performance curve of gas turbine and temperature of compressor inlet, gas turbine load and exhausting temperature, OTC setting point can be got from this curve, so the setting point is relative fixed value, it cannot be modified during operation, the performance curve as Figure 8.

During the normal operation of gas turbine, the gas turbine OTC temperature setting point begin to act, the temperature setting point of Gaoantun power plant is $572{ }^{\circ} \mathrm{C}$, the modification of the compressor inlet temperature function is the value, when the inlet temperature below $15^{\circ} \mathrm{C}$, exhaust temperature value will be lower than $572{ }^{\circ} \mathrm{C}$, when inlet temperature is higher than $15^{\circ} \mathrm{C}$, exhaust temperature value will be higher than $572{ }^{\circ} \mathrm{C}$, the specific function refer to the following logic diagram. In the case of $\mathrm{HCO}$ not run, the exhaust temperature value increased $8{ }^{\circ} \mathrm{C}$ on the basis of the pointas Figure 9.

\section{Conclusion}

In addition to the above several typical closed-loop controller, the pilot gas flow rate, IGV exhaust temperature control and other important closed-loop control are no longer analyzed here. Through the above analysis of Siemens class F gas turbine closed-loop control system, we get the following conclusion:

(1) Siemens gas turbine closed-loop control system uses classic minimum choice control mode, the control links can be undisturbed switching, mutual restriction and protection at the same time. This control method is also used in Siemens steam turbine control, but it is different from the traditional steam turbine.

(2)In the process of Siemens gas turbine closed-loop control, the system often uses the method of open loop and feed forward. Such as air flow and exhaust temperature (OTC) often uses the method of open loop control, the open loop curve is the core of the control, the control parameters is obtained by a large number of trials, ensure the rapidity of the whole operation process.

(3)Many important parameters of Siemens gas turbine are obtained by the scene in the process of the combustion adjustment test. Due to the different gas turbine fuel quality and installation of commissioning situation, so a lot of important parameter is got in the process of on-site adjustment test, and set to the control system, such as curve of gas flow and OTC temperature set point. So after unit operation, the change of the parameters should be pay more attention, many parameters need along with the change of unit operation appropriate to improve and modify.

\section{References}

[1] Cohen, H., Rogers, G. F. C., Saravanamuttoo, H. I. H., and Saravanamutto, H., 1987, "Gas turbine theory."

[2] Breeze, P., 2016, Gas-Turbine Power Generation, Academic Press.

[3] Buckingham, J., FIMechE, C., and McCracken, S., 2016, "Supercritical Organic Rankine Cycle yields useful power and emissions benefits."

[4] Casavant, M. S., Black, K. D., Johnson, D. M., and Danescu, R. I., 2016, "Gas turbine casing thermal control device," Google Patents.

[5] Kraft, R. J., Auerbach, S., and Perri, P., 2016, "GAS TURBINE FAST REGULATION AND POWER AUGMENTATION USING STORED AIR," US Patent 20,160,131,031.

[6] Nordstrom, C. D., and Bowman, R. F., 2016, "Gas turbine engine system with bleed air powered auxiliary engine," Google Patents.

[7] JIn, S., Qi, T., and Shi, L., 2016, Interpretation of control system of Siemens turbo charger. , 
China electric power press Beijing.

[8] Jin, S., Qi, T., and Zhang, B., 2014, Natural gas-steam union cycle electricity technology and appliance guide book, China electric power press, Beijing.

[9] Zhang, S., 2012, Turbo charging engine control system, China electric power press, Beijing. 